\title{
Induction of Heat Shock Proteins by Hyperthermia and Noise Overstimulation in $\mathrm{Hsf1}^{-/}$Mice
}

\author{
Tzz-Wen Gong $^{1}$, Damon A. Fairfield ${ }^{1,2}$, Linne Fullarton ${ }^{1}$, David F. Dolan ${ }^{1}$, Richard A. \\ Altschuler $^{1,2}$, David C. Kohrman ${ }^{1}$, and Margaret I. Lomax ${ }^{1,2}$ \\ ${ }^{1}$ Department of Otolaryngology/Head Neck Surgery, Kresge Hearing Research Institute, University of Michigan, 9301E Medical \\ Sciences Research Building III, SPC 5648, Ann Arbor, MI 48109-5648, USA \\ ${ }^{2}$ Department of Cell and Developmental Biology, University of Michigan, Ann Arbor, MI 48109, USA
}

Received: 6 April 2011; Accepted: 23 August 2011; Online publication: 20 September 2011

\begin{abstract}
Diverse cellular and environmental stresses can activate the heat shock response, an evolutionarily conserved mechanism to protect proteins from denaturation. Stressors activate heat shock transcription factor 1 (HSF1), which binds to heat shock elements in the genes for heat shock proteins, leading to rapid induction of these important molecular chaperones. Both heat and noise stress are known to activate the heat shock response in the cochlea and protect it from subsequent noise trauma. However, the contribution of HSF1 to induction of heat shock proteins following noise trauma has not been investigated at the molecular level. We evaluated the role of HSF1 in the cochlea following noise stress by examining induction of heat shock proteins in $\mathrm{Hsfl}^{+-}$control and $\mathrm{Hsfl}^{-/}$mice. Heat stress rapidly induced expression of $H s p 25$, Hsp 47 , Hsp70.1, Hsp70.3, Hsp84, Hsp86, and Hsp110 in the cochleae of wild-type and $\mathrm{Hsfl}^{+-}$mice, but not in $\mathrm{Hsfl}^{-/}$ mice, confirming the essential role of $\mathrm{HSF} 1$ in mediating the heat shock response. Exposure to broadband noise $(2-20 \mathrm{kHz})$ at $106 \mathrm{~dB}$ SPL for $2 \mathrm{~h}$ produced partial hearing loss. Maximal induction of heat shock proteins occurred $4 \mathrm{~h}$ after the noise. In comparison to heat stress, noise stress resulted in lower induced levels of $H s p 25$, Hsp70.1, Hsp70.3, Hsp86, and Hsp110 in $\mathrm{Hsfl}^{+-}$mice. Induction of these heat shock proteins was attenuated,
\end{abstract}

Correspondence to: Margaret I. Lomax · Department of Otolaryngology/ Head Neck Surgery, Kresge Hearing Research Institute · University of Michigan · 9301E Medical Sciences Research Building III, SPC 5648, Ann Arbor, MI 48109-5648, USA. Telephone: +1-734-6470952; fax: +1-734-6158111; email: mlomax@umich.edu but not completely eliminated, in $\mathrm{Hsf1}^{-/}$mice. These same noise exposure conditions induced genes for several immediate early transcription factors and maximum induction occurred earlier than for heat shock proteins. Thus, additional signaling pathways and transcriptional regulators that are activated by noise probably contribute to induction of heat shock proteins in the cochlea.

Keywords: quantitative RT-PCR, heat shock proteins, noise-induced hearing loss, ABR

\section{INTRODUCTION}

Heat shock (elevated body temperature) elicits the heat shock response, an evolutionarily conserved pathway that protects cells and tissues from numerous environmental stresses (Morimoto et al. 1997; Morimoto 1998; Mathew et al. 2000). This protective effect of heat shock is thought to be achieved via induction of a set of heat shock proteins (HSP) that can act as molecular chaperones to protect proteins from thermal denaturation and to assist in protein refolding. Other mild stresses have also been shown to activate either the entire heat shock response or specific HSPs (Zou et al. 2003; Uchiyama et al. 2007) and offer protection from a subsequent lethal or toxic stress, a phenomenon called acquired (or induced) thermotolerance (Luft et al. 2001). In the mammalian auditory system, activation of the heat shock response by a mild stress, either whole body heat shock (Yoshida et al. 1999) or local hyperthermia (Sugahara et al. 2003), is known to protect 
auditory hair cells in the cochlea from noise overstimulation and prevents hearing loss.

Induction of Hsp70, the major inducible heat shock protein, is often used to assess activation of the heat shock response. Different environmental stressors can also induce HSP70 in the rodent cochlea, suggesting that this important HSP might protect the cochlea. The stressors examined include hyperthermia (the classic heat shock response) (Neely et al. 1991; Dechesne et al. 1992), whole body heat shock (Yoshida et al. 1999), local hyperthermia (Sugahara et al. 2003), transient ischemia (Myers et al. 1992), cisplatin ototoxicity (Oh et al. 2000), and noise overstimulation (Lim et al. 1993; Yoshida et al. 1999; Yoshida and Liberman 2000). Heat shock or overexpression of HSP70 also protects utricular cultures from death of hair cells due to aminoglycoside antibiotics or cisplatin (Taleb et al. 2008, 2009).

In a previous study (Fairfield et al. 2005), we showed that a functional heat shock response is required for complete recovery of hearing following exposure to mild noise. We evaluated both hearing loss and recovery of hearing in $\mathrm{Hsf}^{-/-}$knockout mice by monitoring auditory thresholds following a noise exposure that produced only a transient hearing loss or temporary threshold shift (TTS) in wild-type mice. This same noise exposure caused partial hearing loss and increased loss of outer hair cells in $\mathrm{Hsfl}^{-{ }^{-}}$mice (Fairfield et al. 2005), suggesting that heat shock transcription factor 1 (HSF1) plays an essential role in protecting the cochlea from the initial noise stress or in enhancing the recovery from noise overstimulation. The present study investigated the molecular basis of the heat shock response in the cochleae of normal and $\mathrm{Hsf}^{-1-}$ knockout mouse following noise. We compared the induction of several HSPs following heat shock or noise stress in the cochlea of wild-type and $\mathrm{Hsf}^{-{ }^{-}}$knockout mice to evaluate the contribution of this protective pathway to protection against noise overstimulation.

\section{METHODS}

\section{$\mathrm{Hsfl}^{-{ }^{-}}$mice and genotyping}

$\mathrm{Hsfl}^{+/-}$mice obtained from Dr. I. J. Benjamin (University of Utah) are on a mixed genetic background of 129/Sv and BALB/c (Xiao et al. 1999). Two breeding schemes were used. To obtain wild-type and $\mathrm{Hsfl}^{-/}$mice, $\mathrm{Hsfl}^{+-}$ males and females were intercrossed by brother-sister matings. To increase the yield of nulls, $\mathrm{Hsfl}^{-/-}$males were bred to $\mathrm{Hsfl}^{+-}$females to generate $\mathrm{Hsfl}^{+/-}$and $\mathrm{Hsfl}^{-/}$littermates. Genomic DNA was isolated from tail biopsies of weanling mice with a DNeasy Tissue Kit (Qiagen, Valencia, CA, USA) and was assayed by PCR for presence or absence of both $H s f 1$ and Neo genes to determine the genotypes of individual animals, as described previously (Fairfield et al. 2005). All animals were housed, cared for, and treated in accordance with the regulations of the University Committee on Use and Care of Animals, the University of Michigan.

\section{Heat shock}

We used a heat shock protocol (whole body hyperthermia) that has been shown to protect mice from subsequent noise overstimulation (Yoshida et al. 1999) and to activate HSF1 in the cochlea (Fairfield et al. 2002). Briefly, anesthetized mice were placed in an open incubator at $40^{\circ} \mathrm{C}$ to raise the core body temperature to $3.3^{\circ} \mathrm{C}$ above the initial temperature $\left(41.5-42^{\circ} \mathrm{C}\right)$, monitored with a rectal probe. Mice were maintained at the elevated temperature for $15 \mathrm{~min}$ and then returned to animal cages at room temperature for $30 \mathrm{~min}$ prior to euthanasia. For the sham heat shock controls, anesthetized mice were placed in an unheated oven on a small warming pad to maintain the core body temperature at the initial temperature for a length of time comparable to the heat shock ( $40 \mathrm{~min})$, then were returned to room temperature for $30 \mathrm{~min}$ before euthanasia.

\section{Noise exposure and auditory brainstem response}

Unanesthetized $\mathrm{Hsfl}^{+/-}$and $\mathrm{Hsfl}^{-/-}$mice were placed in individual wire mesh cages in a ventilated sound exposure booth and exposed for $2 \mathrm{~h}$ to a broadband noise (BBN) between 2 and $20 \mathrm{kHz}$ at specific noise intensities of 98,106 , or $120 \mathrm{~dB}$ SPL. To examine the effect of noise on hearing thresholds, we determined the thresholds in the left ear of each animal with pure tone auditory brainstem response (ABR) measurements, as described in detail previously (Fairfield et al. 2005). ABRs were measured at 6,12 , and $24 \mathrm{kHz}$ at least 1 day prior to the noise exposure (baseline ABRs) and then again 2 weeks after the noise exposure.

\section{Isolation of cochlear RNA}

Cochleae were dissected and kept in RNAlater (Ambion; Austin, TX, USA) overnight or longer at $4^{\circ} \mathrm{C}$. RNAlater was removed and cochleae were combined, then frozen at $-80^{\circ} \mathrm{C}$ until all cochleae from each experiment were collected. Each pooled sample contained cochleae dissected from three to four mice. For each RNA sample, the combined cochleae were homogenized in TRIzol (Invitrogen; Carlsbad, CA, USA) with a Tissue Tearor (BioSpec Products; Bartlesville, OK, USA), subjected to total RNA isolation, followed by a Qiagen RNeasy spin column and on-column RNase-free DNase I treatment at room temperature for $15 \mathrm{~min}$ to 
remove residual genomic DNA. RNA quality was assessed by capillary electrophoresis on an Agilent Bioanalyzer 2100 (Agilent Technologies; New Castle, DE, USA); only those samples with discrete $28 \mathrm{~S}$ and $18 \mathrm{~S}$ bands, indicating good RNA quality, were included in subsequent quantitative RT-PCR (qRT-PCR) assays. RNA concentration was determined by UV spectrophotometry. Yields ranged from 0.4 to $0.6 \mu \mathrm{g}$ RNA per mouse cochlea.

\section{Quantitative RT-PCR}

For each RNA sample, first strand complementary DNA (cDNA) was synthesized from total RNA $(1 \mu \mathrm{g})$ with $200 \mathrm{U}$ of RNase H-MMLV reverse transcriptase (SuperScript III, Invitrogen) and oligo (dT) $12-18$ $(500 \mathrm{ng}$ ) in the presence of RNasin (20 U; Promega, Madison, WI, USA) in a final volume of $20 \mu \mathrm{l}$. The reaction was incubated at $50^{\circ} \mathrm{C}$ for $1 \mathrm{~h}$, heated at $70^{\circ} \mathrm{C}$ for $15 \mathrm{~min}$ to inactivate reverse transcriptase, and treated with RNase $\mathrm{H}$ (2 U; Promega) at $37^{\circ} \mathrm{C}$ for $15 \mathrm{~min}$ to remove RNA templates. The resulting cDNAs were diluted 1:10 with water and stored as aliquots at $-20^{\circ} \mathrm{C}$. For each transcript assayed, realtime PCR was performed in triplicate on each cDNA sample in an Applied Biosystems Prism 7000 Sequence Detection System with gene-specific TaqMan probes (Assays-on-Demand or Assays-by-Design; Applied Biosystems; Foster City, CA, USA). For mouse Hsp70.1 and 70.3 , we used gene-specific TaqMan probes designed to the $3^{\prime}$ UTRs (ABI). For each gene, we determined the $C_{\mathrm{T}}$, the cycle number at which the fluorescent signals were above the background level, but still in the early exponential phase of amplification. Average $C_{\mathrm{T}}$ values were normalized to that of ribosomal protein S16. The relative difference in transcript level between two samples for any given gene was calculated based on the ratio of the normalized $C_{\mathrm{T}}$ value in the experimental sample to that of the control. The same threshold was used for both genes of interest and S16 (internal control) across all samples. The difference in $C_{\mathrm{T}}$ between the gene of interest (gene "X") and S16 for any given RNA sample was defined as $\Delta C_{\mathrm{T}}(\mathrm{X})$. The difference in $\Delta C_{\mathrm{T}}(\mathrm{X})$ between two samples (e.g., induced vs. uninduced control or noise-exposed vs. unexposed control) was defined as $\Delta \Delta C_{\mathrm{T}}(\mathrm{X})$, which represented a relative difference in expression of gene $X$ (Latif et al. 2001). Fold change was calculated after adjusting for amplification efficiency of the PCR assay for the corresponding gene. In all figures, fold change is the ratio of normalized transcript levels in treated groups to normalized levels in the unstressed control group of the same genotype. Since fold change is a relative term and there are no standard errors in the control group (values set to 1 ), $t$ tests were applied for statistical comparisons of basal gene expression in the mutant vs. wild-type controls, and in treated vs. unstressed controls. In the study, assessing induction of each Hsp gene following exposure to different intensity of noise, we performed one-way ANOVA with three levels, followed by multiple post hoc comparisons between pairs of intensity levels. In all figures, error is reported as the standard error of the mean (SEM).

\section{RESULTS}

Survey of HSP induction in the mouse cochlea following heat shock

Most studies of heat shock in the cochlea have examined induction of HSP70; however, there are several families of HSPs, each family having somewhat different molecular chaperone functions. We therefore performed a heat shock experiment and surveyed the induction of representative HSP genes from several families. As has been observed in other systems, in wild-type mice, the two inducible genes for mouse HSP70, i.e., Hsp70.1 and Hsp70.3, showed robust $\sim 1,000$-fold induction following heat shock (Table 1). Of the other HSP genes tested, all except $H s p 32$ were induced at least 2-fold, ranging from 28fold to 2.9-fold: Hsp25 (28), Hsp47 (14), Hsp84/ $H s p 90 \beta$ (2.9), Hsp86/Hsp90a (5.3), and Hsp110 (8.3). The genes that showed $>2$-fold induction in wild-type mice were then tested in Hsfl knockout mice; none showed significant increases following heat shock. Based on this initial survey, we selected a subset of HSP target genes representing different families of HSPs for subsequent molecular studies: Hsp25, Hsp86, $H s p 70.1$, and Hsp70.3. Several non-HSP genes known to be regulated by HSF1 in other systems or to be involved in oxidative stress were also tested but were not induced by heat stress in the cochlea: the amyloid precursor protein; clusterin/ApoJ, a protein involved in apoptosis, or $\mathrm{Cu} / \mathrm{Zn}$ superoxide dismutase, known to be involved in oxidative stress.

Induction of HSP70 in the mouse cochlea following heat shock requires HSF1

We performed a quantitative analysis of the heat shock response in the mouse cochlea by measuring the change in expression of the two inducible Hsp70 genes (Hsp70.1 and Hsp70.3) in $H_{s f 1^{+-}}$(Fig. 1, white bars, HS) and $\mathrm{Hsfl}^{-1-}$ mice (Fig. 1, black bars, HS). Both Hsp70 genes showed similar robust induction ( 1,000-fold) following heat shock in heterozygotes, but not in knockout mice. Since handling and restraint stress has been shown to affect glucocorticoid levels and to protect mice from acoustic injury (Wang and Liberman 2002), we also subjected Hsf1 heterozygotes (Fig. 1, white bars, SM) and knockouts 
TABLE 1

Survey of genes induced by heat shock in the cochlea of wild-type and $\mathrm{Hsf1}^{-1-}$ mice

\begin{tabular}{|c|c|c|c|c|}
\hline \multirow[b]{2}{*}{ Common name } & \multirow[b]{2}{*}{ Gene symbol } & \multirow[b]{2}{*}{ GeneBank ID } & \multicolumn{2}{|c|}{ Fold change $^{a}$} \\
\hline & & & $H s f 1^{+/+}$ & $H s f 1^{-1}$ \\
\hline Hsp70.1 & Hspa1b & NM_010478 & 975 & 1.0 \\
\hline Hsp70.3 & Hspa1a & NM_010479 & 1,300 & 1.0 \\
\hline Hsp25 & Hspb1 & NM_013560 & 28 & 1.00 \\
\hline Hsp47 & Serpinh1 & NM_009825 & 14.0 & ND \\
\hline Hsp110 & Hsp110 & NM_013559 & 8.3 & ND \\
\hline 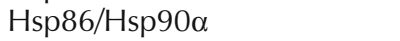 & Hspca & NM_010480 & 5.3 & 1.0 \\
\hline Hsp84/Hsp90ß & $\mathrm{Hspcb}$ & NM_008302 & 2.9 & 1.0 \\
\hline Hsp32 & Hmox1 & NM_010442 & 1.6 & ND \\
\hline Amyloid beta precursor & App & NM_007471 & $1.0^{\mathrm{b}}$ & 1.0 \\
\hline Clusterin & Clu & NM_013492 & 1.0 & 1.0 \\
\hline Superoxide dismutase & Sod1 & NM_011434 & 1.0 & ND \\
\hline Hypoxia inducible factor $1 \alpha$ & Hif1a & NM_176958 & 1.0 & ND \\
\hline
\end{tabular}

ND not determined

a Fold change: ratio of mRNA in RNA from induced/RNA from control (uninduced) cochleae

${ }^{\mathrm{b}} \mathrm{A}$ ratio of 1.0 indicates no significant change between the control and the heat-shocked mice

(Fig. 1, black bars, SM) to a sham heat shock treatment (see "Methods") as an additional control. These manipulations did not induce HSP70 genes significantly in either wild-type or $\mathrm{Hsfl}^{-/-}$mice. These results demonstrated that the cochlea can mount a vigorous response to heat shock and that HSF1 is necessary for this response.

\section{HSF1 affects basal level of HSP gene expression}

We observed that the basal expression of the Hsp70 genes was lower in nulls than in heterozygotes (ratios $<1.0$; Fig. 1). We therefore analyzed basal levels of several HSP genes in unstressed nulls ( $n=9$ RNA samples) and heterozygotes ( $n=7$ samples) in six independent experiments (Fig. 2). When compared

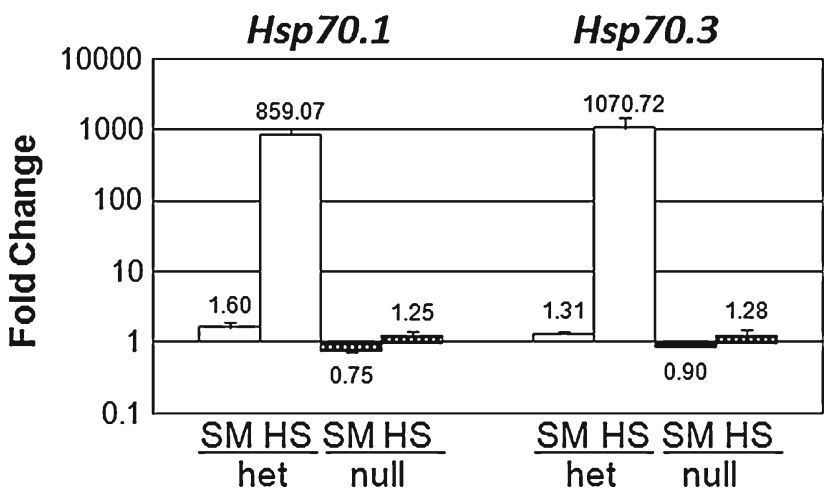

FIG. 1. Induction of genes for Hsp70 by heat stress in $\mathrm{Hsf1}^{+/}$and $\mathrm{Hsfl}^{-\digamma}$ mice. Mice (three mice per sample) were subjected to heat shock $(H S, n=4)$, a sham procedure $(S M, n=2)$, or no treatment (control, $n=3$ ) prior to euthanasia. Hsp70.1 or Hsp70.3 mRNA levels were determined by qRT-PCR and normalized to S16 mRNA. White bars represent fold change in $\mathrm{Hsf1}^{+/}$mice and black bars in $\mathrm{Hsf1}^{-/-}$ mice. Bars represent SEM. by $t$ test, the basal level of each gene was significantly lower in the null than in the corresponding heterozygotes $(p<0.001)$. Thus, loss of HSF1 affects basal transcription of HSP genes in the cochlea. A similar effect on basal transcription was noted in a genomic analysis of the heat shock response (Trinklein et al. 2003).

\section{Noise stress induces HSPs}

In a previous study (Fairfield et al. 2005), we demonstrated that HSF1 offers protection from noise overstimulation. In response to a noise exposure (98 dB SPL BBN, 2-20 kHz, $2 \mathrm{~h}$ ) that produces a TTS, the ABRs of wild-type mice returned to normal,

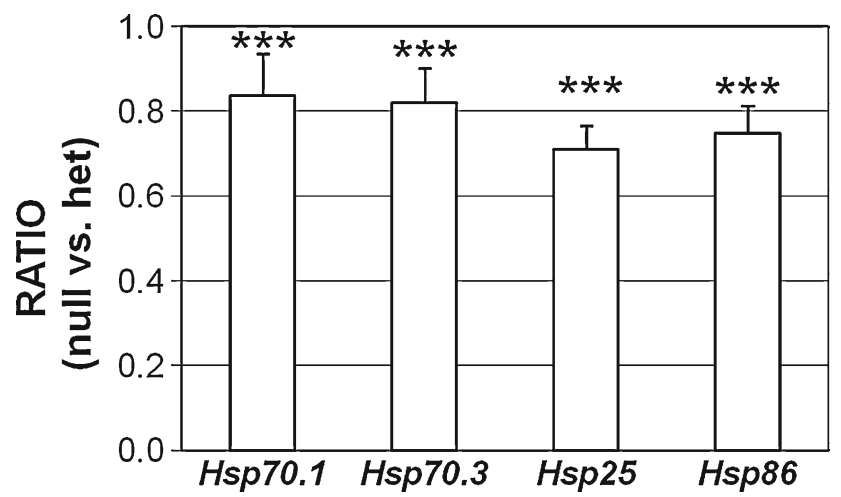

FIG. 2. Basal levels of HSP mRNAs in the cochlea of $\mathrm{Hsfl}^{-/}$vs. $\mathrm{Hsfl}^{+-}$mice. qRT-PCR was performed on total RNA from the cochleae of unstressed $\mathrm{Hsfl}^{-\digamma}(n=9)$ and $\mathrm{Hsfl}^{+-}$mice $(n=7)$, from six independent experiments. Ratios indicate the HSP mRNA levels in $\mathrm{Hsfl}^{-/-}$mice compared to their paired $\mathrm{Hsfl}^{+/}$mice within each experiment. Ratios were subjected to paired Student'st test. Asterisks denote statistically significant differences: ${ }^{* * *} p<0.001$. Bars indicate SEM. 
whereas ABRs in Hsf1 knockout mice did not. Although complete recovery of auditory thresholds required HSF1, we did not detect induction of Hsp70 genes when assayed $30 \mathrm{~min}$ following the noise stress, as in the heat shock experiment (data not shown). This suggested either that the noise exposure was not sufficient for significant induction of HSPs in RNA from whole cochlea, or that the sampling time was not optimal. We therefore noise-exposed mice at a higher noise intensity (106 dB SPL) and assayed induction of HSP genes at 1, 2, 4, 9, 12, and $24 \mathrm{~h}$ following the noise exposure (Fig. 3) to determine the kinetics of induction. Expression of all four HSP genes (Hsp70.1, Hsp70.3, Hsp25, and Hsp86) showed maximal induction at $4 \mathrm{~h}$ following exposure to 106-dB noise for $2 \mathrm{~h}$.

We also investigated induction of HSPs at increasing noise intensities, sampling at time of peak induction, i.e., $4 \mathrm{~h}$ after noise exposure. At this later time point $(4 \mathrm{~h})$, noise clearly resulted in significant induction, shown by one-way ANOVA, in HSP gene expression. Noise intensity of $98 \mathrm{~dB}$ SPL was capable of mounting an apparent 2- to 3-fold induction of both $H s p 70.1$ and Hsp70.3; however, this increase was not significant for Hsp70.3 $(p \leq 0.05)$. Both Hsp70 genes showed statistically significant increases (8-fold to 10 -fold) at the higher noise intensities (106 dB SPL and $120 \mathrm{~dB}$ ) compared to $98 \mathrm{~dB}$ SPL (Fig. 4). The differences between 106 and $120 \mathrm{~dB}$ SPL, however, were not statistically significant. Since exposure to $106 \mathrm{~dB}$ SPL BBN $(2-20 \mathrm{kHz})$ for $2 \mathrm{~h}$ yielded maximum induction for all four genes, we examined the physiological consequence of this noise exposure by measuring threshold shifts. Auditory thresholds (ABRs) were determined before and 14 days following the noise exposure (Fig. 5). We observed a slight

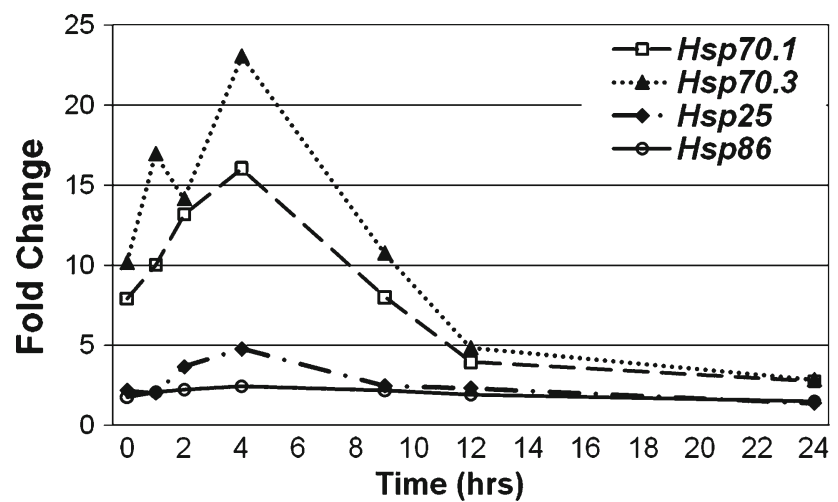

FIG. 3. Time course of HSP gene induction following noise stress $\mathrm{Hsf1}^{+-}$mice were exposed to BBN (106 dB SPL, 2-20 kHz, $2 \mathrm{~h}$ ). Mice (four per sample) were euthanized either immediately after the noise exposure $(t=0)$ or at $1,2,4,9,12$, and $24 \mathrm{~h}$ following noise. Control mice were not subjected to the noise stress. Cochlear RNA was isolated and subjected to real-time qRT-PCR to determine relative gene expression. Fold change is the ratio of normalized transcript level in the noise-exposed group to the control group. For all HSPs tested, maximum induction occurred at $4 \mathrm{~h}$ after noise.

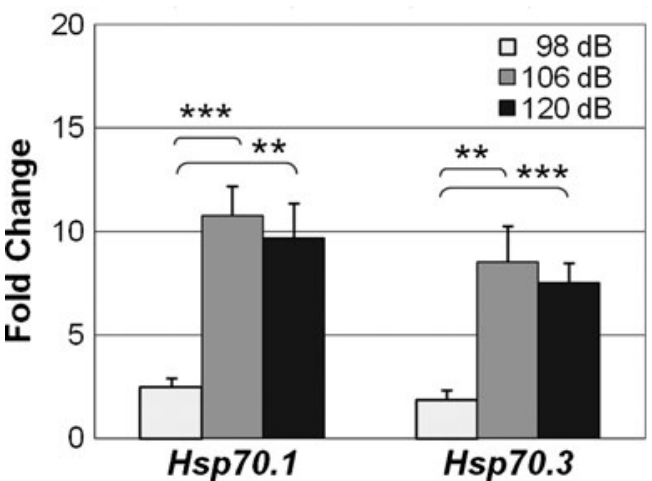

FIG. 4. Effect of noise intensity on induction of HSP genes. $\mathrm{Hsfl}^{+/}$ mice (four mice per sample) were exposed to noise for $2 \mathrm{~h}$ and euthanized $4 \mathrm{~h}$ after cessation of noise. Cochlear RNA was subjected to qRT-PCR: $98 \mathrm{~dB}(n=7), 106 \mathrm{~dB}(n=9)$, and $120 \mathrm{~dB}(n=6)$. Fold change is the ratio of values for noise-exposed mice relative to unexposed controls. Values at $98 \mathrm{~dB}$ were compared to control values by $t$ test. Differences among the three noise intensities were evaluated by one-way ANOVA, followed by post hoc pairwise comparisons to determine which differences account for the result of the more inclusive test. The $p$ values for 106 and $120 \mathrm{~dB}$ vs. $98 \mathrm{~dB}$ were 0.0011 and 0.0002 , respectively, below the sequential Bonferroni criterion for table-wide significance of multiple comparisons. ${ }^{* *} p<0.01 ;{ }^{* * *} p<0.001$. Bars indicate SEM.

permanent threshold shift (PTS) 2 weeks after noise overstimulation, with an average increase in auditory threshold of $12 \mathrm{~dB}$ at $12 \mathrm{kHz}$ and $\sim 20 \mathrm{~dB}$ at $24 \mathrm{kHz}$ (Fig. 4).

Induction of HSPs by noise stress in $\mathrm{Hsfl}^{+/-}$ and $\mathrm{Hsfl}^{-/}$mice

Induction of HSPs following noise stress could be mediated entirely by HSF1, as in the heat shock response, or might be regulated by additional tran-

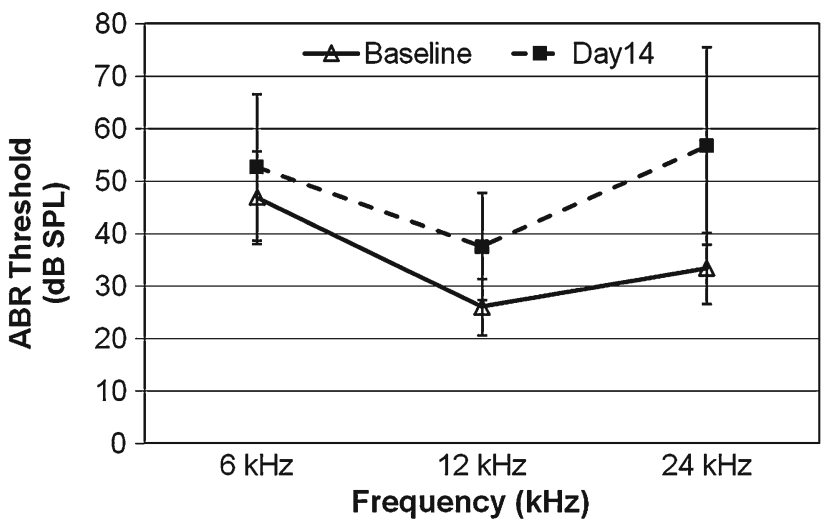

FIG. 5. Effect of noise exposure on auditory thresholds. Baseline ABRs were measured on $\mathrm{Hsf1}^{+/}$mice $(n=15) 1-3$ days prior to noise exposure (106 dB SPL, 2-20 kHz BBN, 2 h). ABRs were repeated 14 days after noise exposure. This noise exposure condition resulted in a slight permanent threshold shift (average of $12 \mathrm{~dB}$ SPL hearing loss at $12 \mathrm{kHz}$ and $\sim 20 \mathrm{~dB}$ SPL loss at $24 \mathrm{kHz}$ ) at 2 weeks after noise overstimulation. Bars represent SEM. 
scription factors. To distinguish between these alternatives, we measured HSP induction following exposure to $106 \mathrm{~dB}$ SPL BBN in $\mathrm{Hsfl}^{+-}$and $\mathrm{Hsf1}^{-/-}$mice (Fig. 6). Induction of $H s p 70.1$ and $H s p 70.3$ decreased in $\mathrm{Hsfl}^{-{ }^{-}}$ mice, but in contrast to the heat shock response, it was not eliminated. Hsp25 and Hsp86 were not highly induced following noise, but showed a significant decrease in $\mathrm{Hsfl}^{-\mathcal{-}}$ mice (Fig. 6). These results suggest that noise overstimulation activates not only HSF1, but also additional transcription factors that regulate expression of these HSP genes.

Induction of immediate early genes

following noise stress

We therefore examined the time course of expression of several immediate early genes (IEGs) that we showed were induced following noise overstimulation in the rat cochlea (Cho et al. 2004), including the important transcription factors c-Fos and Egrl and the protective cytokine leukemia inhibitory factor (LIF). The noise intensities used in this earlier study of the molecular response to noise overstimulation caused some PTS. Induction of these IEGs following exposure to $106 \mathrm{~dB}$ SPL noise overstimulation in the mouse (Fig. 7) was determined on the same RNA samples used for the induction of Hsp genes shown in Figure 3. This analysis demonstrated that these IEGs are indeed induced following exposure to $106 \mathrm{~dB}$ SPL $\mathrm{BBN}$, but with somewhat different kinetics. Induction of $c$-fos and $c$-jun precedes induction of HSPs. Thus, induction of some HSPs by noise in $\mathrm{Hsfl}^{-/-}$mice may be mediated through increases in intracellular calcium signaling and activation of CREB, as we proposed for the induction of these genes following noise overstimulation in the rat (Cho et al. 2004).

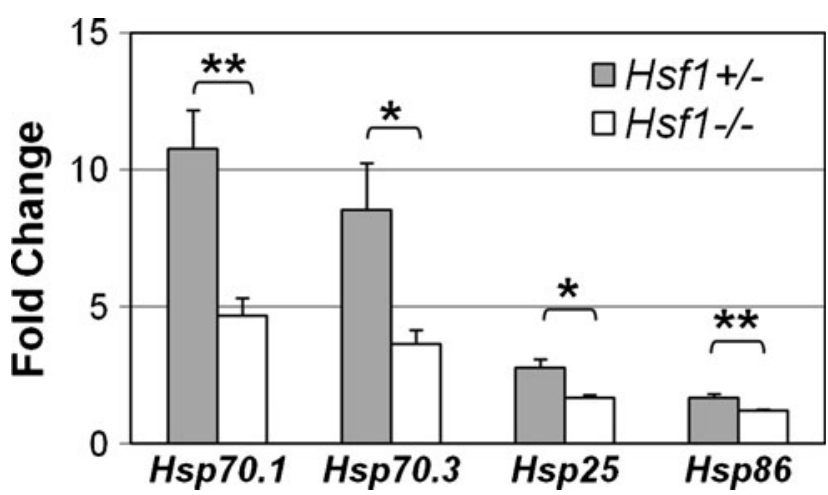

FIG. 6. Induction of Hsp genes following noise in $\mathrm{Hsfl}^{+/}$and $\mathrm{Hsf1}^{-/}$mice. $\mathrm{Hsf1}^{+/}$or $\mathrm{Hsf1}^{-/}$mice were exposed to $106 \mathrm{~dB} \mathrm{SPL}$ BBN for $2 \mathrm{~h}$ and euthanized $4 \mathrm{~h}$ after noise exposure $(n=9$ for each genotype). Induction of Hsps was analyzed by qRT-PCR. Fold change was calculated as in Figure 1 and subjected to unpaired Student'st test; ${ }^{*} p<0.05 ;{ }^{* *} p<0.01$. Bars represent SEM.

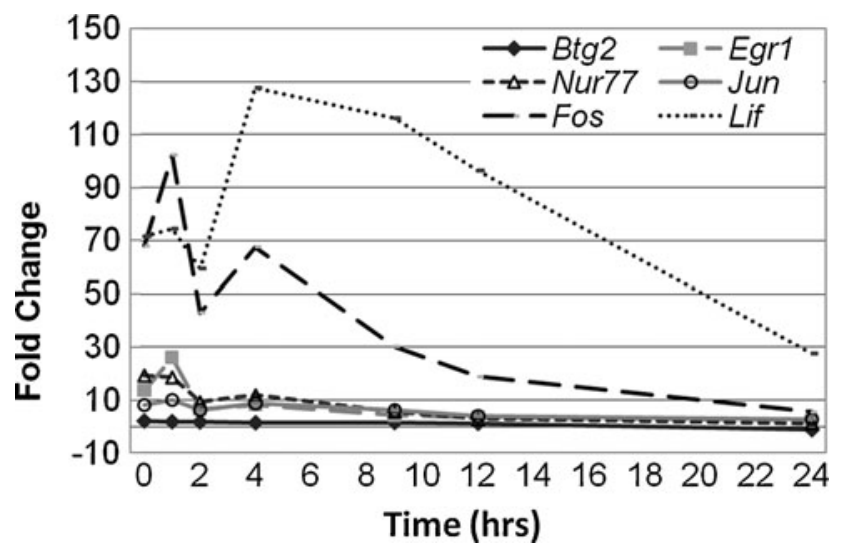

FIG. 7. Time course of IEG induction following noise stress. RNA samples used for the time course experiment (see Fig. 3) were also assayed for several IEGs by qRT-PCR as in Figure 3. Most IEGs tested showed maximum induction at $1 \mathrm{~h}$, although IEGs such as c-Fos and LIF showed a second peak of activity at $4 \mathrm{~h}$.

\section{DISCUSSION}

In mammals, HSF1 acts as a master regulator of the inducible heat shock response. The mechanism of HSF1 activation is well understood. The Hsf1 gene is expressed constitutively, although HSF1 monomers are transcriptionally inactive due to intramolecular interactions through leucine-repeat regions. This folded form of HSF1 is further stabilized by the molecular chaperones Hsp70 and Hsp90 (Morimoto 1998). Activation of HSF1 monomers to the transcriptionally active trimer form is a complex, multi-step process initiated by the accumulation of non-native proteins. Most stressors generate denatured proteins that compete with HSF1 for binding to Hsp70 and Hsp90. These unfolded HSF1 monomers form trimers that are transcriptionally active and bind to heat shock elements in the promoters of target genes, leading to induction of HSPs (Pirkkala et al. 2001) and other target genes (Trinklein et al. 2004). In addition, stress-related kinases such as JNK and MAPK phosphorylate HSF1 trimers on Ser residues, enhancing DNA binding and transcriptional activation of HSP genes (Morimoto et al. 1997; Guettouche et al. 2005). Finally, the oxidation state of the cell also can affect the activation state of HSF1 (Ahn and Thiele 2003). Thus, HSF1 integrates multiple signals from several different stress pathways

Induction of HSPs is an accurate measure of HSF1 activation, and the highly inducible Hsp70 genes provide a sensitive assay. Hsp70 proteins are involved in a wide range of protein folding processes, including correct folding of newly synthesized proteins, transport of proteins across membranes, refolding of misfolded and aggregated proteins, and the control of the activity of regulatory proteins (Bukau and Horwich 1998; Bukau et al. 2006). The mechanism 
through which Hsp70 proteins act as molecular chaperones to assist protein refolding has been elucidated recently (Bukau et al. 2006). Multiple Hsp70 genes encode specialized Hsp70 proteins found in each organelle and compartment in the cell. In addition, two inducible Hsp70s provide additional protection against severe stress conditions. In this study, the two inducible genes for Hsp70, Hsp70.1 and Hsp70.3, showed the greatest increase in messenger RNA (mRNA) levels following both stresses, consistent with their role as backup or reserve protective systems.

We have used a genetic approach to assess the contribution of the heat shock response to protection from noise overstimulation. By examining the effects of heat or other stressors in both normal and HsfI knockout mice, it is possible to determine the contribution of activated HSF1 to the induction of the stress response. Induction by heat in wild types or heterozygotes was more robust and more rapid than induction by noise. Heat stress did not induce HSPs in $\mathrm{Hsfl}^{-/-}$mice, confirming the essential role of HSF1 in regulating induction of HSPs by heat. These results are also consistent with several published studies demonstrating that induction of HSPs by heat requires functional HSF1.

Induction of HSPs by noise is more complex. In our previous study, both wild-type and $H s f 1^{-/-}$knockout mice were exposed to a noise level that produced only a TTS in wild-type mice. The same noise intensity caused a partial hearing loss and increased loss of outer hair cells in $\mathrm{Hsfl}^{-/-}$mice (Fairfield et al. 2005), suggesting that HSF1 plays an essential role either in protecting the cochlea from the initial noise stress or enhancing the recovery from noise overstimulation. In this study, we evaluated the heat shock response in the cochleae of normal $\mathrm{Hsfl}^{+-}$heterozygotes and Hsf1 knockout mice following a more intense noise exposure-BBN (2-20 kHz) at $106 \mathrm{~dB}$ SPL for $2 \mathrm{~h}-$ that produced a slight PTS. Increasing the noise intensity was necessary to obtain sufficient activation of HSF1 and thus induction of HSPs by noise to evaluate the effect in knockout mice.

To evaluate induction of HSPs following noise exposure, it was necessary to optimize the assay, since induction occurred later and to lower levels than following heat stress. Induction of HSPs was reduced, but was not eliminated, in $\mathrm{Hsfl}^{-/-}$mice, indicating that other transcription factors can regulate expression of HSPs following noise overstimulation. We therefore examined induction of several immediate early genes known to be induced by noise overstimulation, including the transcription factors $c$-fos, Egrl, and Nur77/TR3 (Cho et al. 2004). Induction of these and other immediate early genes preceded induction of HSPs, suggesting that noise overstimulation activates additional signaling pathways in the mouse cochlea that might regulate expression of HSPs following noise. Induction of Hsp70 genes may be regulated by one or more of the immediate early genes we have shown to be activated by noise. A complex of c-fos and c-Jun (or a related family member) comprises the AP-1 transcriptional regulator, which may regulate expression of Hsp70 genes independently of HSF1. Several studies, including ours, have implicated the AP-1 transcription complex in the response to noise overstimulation (Williams et al. 1989).

Several lines of evidence support the protective role of the heat shock response. Prior activation of the heat shock response by a mild stress protects cells from a subsequent lethal or toxic stress, a phenomenon called acquired (or induced) thermotolerance (Luft et al. 2001). Several studies showed that acquired thermotolerance, either from whole body heat shock (Yoshida et al. 1999) or local hyperthermia (Sugahara et al. 2003), protects auditory hair cells in the cochlea from noise overstimulation and prevents hearing loss. Transgenic and knockout mouse models have contributed to our understanding of the protective role of the heat shock response in mammals. Hsfl knockouts are often more sensitive to stressors (Yan et al. 2002; Wirth et al. 2003; Christians and Benjamin 2005). Indeed, Hsfl knockouts have provided genetic evidence for the protective role of the heat shock response in the cochlea. $\mathrm{Hsfl}^{-1-}$ mice (Xiao et al. 1999) are viable, have normal auditory thresholds, but are more sensitive to noise (Sugahara et al. 2003; Fairfield et al. 2005). Heat shock also protects against hair cell death due to either aminoglycosides or cisplatin toxicity in an in vitro utricular culture model (Cunningham and Brandon 2006; Taleb et al. 2008). Conversely, transgenic mice expressing a constitutively active form of HSF1 that forms trimers spontaneously in the absence of stress are more resistant to and thus protected from various stressors (Wagstaff et al. 1998; Uchiyama et al. 2007). Such mouse models have not yet been tested for protection of auditory function.

Mammals have two additional well-characterized HSF genes (HSF2 and HSF4) and a recently identified mammalian form of HSF3, thought to be present only in birds. Targeted mutation of each HSF gene has defined the contribution of each of these important transcription factors to different environmental, developmental, and physiological stresses (Christians and Benjamin 2006). HSF2 was originally thought to function primarily in development, but more recent studies suggest that HSF2 may interact with HSF1 to modulate induction of HSPs (Ostling et al. 2007). HSF4 has been implicated in brain and lens development (Fujimoto et al. 2004; Christians and Benjamin 2006). It is unlikely that either of these HSFs compensate for the loss of HSF1 in Hsf1 KO mice.

Noise-induced hearing loss (NIHL) is a major health problem in industrialized countries and may 
also contribute to age-related hearing loss or presbycusis. Consequently, means to protect the ear against NIHL would be highly desirable. Exposure to intense noise generates mechanical forces that damage the stereocilia on hair cells. In addition to the mechanical damage to inner ear structures, the generation of reactive oxygen species (ROS) is a major source of cochlear damage (Henderson et al. 2006). ROS form adducts with DNA, protein, and lipids and have been shown to contribute to the induction of HSPs (Gorman et al. 1999). Oxidized and partially unfolded proteins can trigger the heat shock response by competing with HSF1 for binding to chaperone proteins. Thus, activation of HSPs following noise exposure may in part be mediated through ROS.

Several small molecules known to activate HSF1 have been suggested as therapeutic agents for neurological disorders involving protein aggregation. For example, celastrol, a natural product, upregulates HSP gene expression through indirect activation of HSF1 (Zhang and Sarge 2007). Geranylgeranylacetone, an anti-ulcer agent, activates HSF1 in the cochlea and prevents acoustic injury in guinea pigs (Mikuriya et al. 2005). Bimoclomol acts as a HSP co-inducer by prolonging the activation of HSF1 (Hargitai et al. 2003). Recently, additional classes of synthetic small molecule modulators of HSF1 activity have been identified through a genetic screen in yeast (Neef et al. 2010). These molecules have the potential to activate HSF1, induce HSPs in the cochlea to low levels, and protect against acute noise stress.

\section{ACKNOWLEDGMENTS}

This study was supported by NIH grants P01 AG025164, P30 DCO5188, and NIH/NIDCD T32 DC00011 (DAF). We thank Sarah A. Davis for excellent technical assistance; Ariane Kanicki for assisting in dissecting mouse cochleae; and Gary Dootz, Lisa Kabara, and Jen Benson of the KHRI Physiology Core for assistance with noise exposure experiments and ABR data. We also thank Don Swiderski for assistance with statistical analysis.

\section{REFERENCES}

Ahn SG, Thiele DJ (2003) Redox regulation of mammalian heat shock factor 1 is essential for Hsp gene activation and protection from stress. Genes Dev 17:516-528

Bukau B, Horwich AL (1998) The Hsp70 and Hsp60 chaperone machines. Cell 92:351-366

Bukau B, Weissman J, Horwich A (2006) Molecular chaperones and protein quality control. Cell 125:443-451

Cho Y, Gong TW, Kanicki A, Attschuler RA, Lomax MI (2004) Noise overstimulation induces immediate early genes in the rat cochlea. Brain Res Mol Brain Res 130:134-148
Christians ES, Benjamin IJ (2005) The stress or heat shock (HS) response: insights from transgenic mouse models. Methods $35: 170-175$

Christians ES, Benjamin IJ (2006) Heat shock response: lessons from mouse knockouts. Handb Exp Pharmacol 139-152

Cunningham LL, Brandon CS (2006) Heat shock inhibits both aminoglycoside- and cisplatin-induced sensory hair cell death. J Assoc Res Otolaryngol 7:299-307

Dechesne CJ, Kim HN, Nowak TS Jr, Wenthold RJ (1992) Expression of heat shock protein, HSP72, in the guinea pig and rat cochlea after hyperthermia: immunochemical and in situ hybridization analysis. Hear Res 59:195-204

Fairfield DA, Kanicki AC, Lomax MI, Altschuler RA (2002) Expression and localization of heat shock factor (Hsf) 1 in the rodent cochlea. Hear Res 173:109-118

Fairfield DA, Lomax MI, Dootz GA, Chen S, Galecki AT, Benjamin IJ, Dolan DF, Altschuler RA (2005) Heat shock factor 1-deficient mice exhibit decreased recovery of hearing following noise overstimulation. J Neurosci Res 81:589-596

Fujimoto M, Izu H, Seki K, Fukuda K, Nishida T, Yamada S, Kato K, Yonemura S, Inouye S, Nakal A (2004) HSF4 is required for normal cell growth and differentiation during mouse lens development. EMBO J 23:4297-4306

Gorman AM, Heavey B, Creagh E, Cotter TG, Samali A (1999) Antioxidant-mediated inhibition of the heat shock response leads to apoptosis. FEBS Lett 445:98-102

Guettouche T, Boellmann F, Lane WS, Voellmy R (2005) Analysis of phosphorylation of human heat shock factor 1 in cells experiencing a stress. BMC Biochem 6:4

Hargitai J, Lewis H, Boros I, Racz T, Fiser A, Kurucz I, Benjamin I, Vigh L, Penzes Z, Csermely P, Latchman DS (2003) Bimoclomol, a heat shock protein co-inducer, acts by the prolonged activation of heat shock factor-1. Biochem Biophys Res Commun 307:689-695

Henderson D, Bielefeld EC, Harris KC, Hu BH (2006) The role of oxidative stress in noise-induced hearing loss. Ear Hear 27:1-19

Latif S, Bauer-Sardina I, Ranade K, Livak KJ, Kwok PY (2001) Fluorescence polarization in homogeneous nucleic acid analysis II: 5'-nuclease assay. Genome Res 11:436-440

Lim HH, Jenkins OH, Myers MW, Miller JM, Altschuler RA (1993) Detection of HSP 72 synthesis after acoustic overstimulation in rat cochlea. Hear Res 69:146-150

Luft JC, Benjamin IJ, Mestril R, Dix DJ (2001) Heat shock factor 1mediated thermotolerance prevents cell death and results in G2/M cell cycle arrest. Cell Stress Chaperones 6:326-336

Mathew A, Shi Y, Jolly C, Morimoto Ri (2000) Analysis of the mammalian heat-shock response. Inducible gene expression and heat-shock factor activity. Methods Mol Biol 99:217-255

Mikuriya T, Sugahara K, Takemoto T, Tanaka K, Takeno K, Shimogori H, NAKAI A, YAMASHITA H (2005) Geranylgeranylacetone, a heat shock protein inducer, prevents acoustic injury in the guinea pig. Brain Res 1065:107-114

Mовімото RI (1998) Regulation of the heat shock transcriptional response: cross talk between a family of heat shock factors, molecular chaperones, and negative regulators. Genes Dev 12:3788-3796

Morimoto RI, KLine MP, Bimston DN, Cotto JJ (1997) The heatshock response: regulation and function of heat-shock proteins and molecular chaperones. Essays Biochem 32:17-29

Myers MW, Quirk WS, Rizk SS, Miller JM, Altschuler RA (1992) Expression of the major mammalian stress protein in the rat cochlea following transient ischemia. Laryngoscope 102:981-987

Neef DW, Turski ML, Thiele DJ (2010) Modulation of heat shock transcription factor 1 as a therapeutic target for small molecule intervention in neurodegenerative disease. PLoS Biol 8:e1000291

Neely JG, Thompson AM, Gower DJ (1991) Detection and localization of heat shock protein 70 in the normal guinea pig cochlea. Hear Res 52:403-406 
Oh SH, Yu WS, Song BH, Lim D, Koo JW, Chang SO, Kim CS (2000) Expression of heat shock protein 72 in rat cochlea with cisplatininduced acute ototoxicity. Acta Otolaryngol 120:146-150

Ostuing P, Bjork JK, Roos-Mattjus P, Mezger V, Sistonen L (2007) Heat shock factor 2 (HSF2) contributes to inducible expression of hsp genes through interplay with HSF1. J Biol Chem 282:7077-7086

Pirkkala L, Nykanen P, Sistonen L (2001) Roles of the heat shock transcription factors in regulation of the heat shock response and beyond. FASEB J 15:1118-1131

Sugahara K, Inouye S, Izu H, Katoh Y, Katsuki K, Takemoto T, Shimogori H, Yamashita H, NaKai A (2003) Heat shock transcription factor HSF1 is required for survival of sensory hair cells against acoustic overexposure. Hear Res 182:88-96

Taleb M, Brandon CS, Lee FS, Lomax Mi, Dillmann WH, Cunningham LL (2008) Hsp70 inhibits aminoglycoside-induced hair cell death and is necessary for the protective effect of heat shock. J Assoc Res Otolaryngol 9:277-289

Taleb M, Brandon CS, Lee FS, Harris KC, Dillmann WH, Cunningham LL (2009) Hsp70 inhibits aminoglycoside-induced hearing loss and cochlear hair cell death. Cell Stress Chaperones 14:427-437

Trinklein ND, Aldred SJ, Saldanha AJ, Myers RM (2003) Identification and functional analysis of human transcriptional promoters. Genome Res 13:308-312

Trinklein ND, Murray JI, Hartman SJ, Botstein D, Myers RM (2004) The role of heat shock transcription factor 1 in the genome-wide regulation of the mammalian heat shock response. Mol Biol Cell 15:1254-1261

Uchiyama T, Atsuta H, Utsugi T, Oguri M, Hasegawa A, Nakamura T, Naka A, Nakata M, Maruyama I, Tomura H, Okajima F, Tomono S, KaWAZU S, NAGAI R, KuRABAyASHI M (2007) HSF1 and constitutively active HSF1 improve vascular endothelial function (heat shock proteins improve vascular endothelial function). Atherosclerosis 190:321-329
Wagstaff MJ, Smith J, Collaco-Moraes Y, de Belleroche JS, Voellmy R, Coffin RS, Latchman DS (1998) Delivery of a constitutively active form of the heat shock factor using a virus vector protects neuronal cells from thermal or ischaemic stress but not from apoptosis. Eur J Neurosci 10:3343-3350

WAng Y, Liberman MC (2002) Restraint stress and protection from acoustic injury in mice. Hear Res 165:96-102

Williams GT, McClanahan TK, Morimoto RI (1989) E1a transactivation of the human HSP70 promoter is mediated through the basal transcriptional complex. Mol Cell Biol 9:2574-2587

Wirth D, Christians E, Li X, Benjamin IJ, Gustin P (2003) Use of Hsfl $(-/-)$ mice reveals an essential role for HSF1 to protect lung against cadmium-induced injury. Toxicol Appl Pharmacol 192:12-20

Xiao X, Zuo X, Davis AA, McMillan DR, Gurry BB, Richardson JA, Benjamin IJ (1999) HSF1 is required for extra-embryonic development, postnatal growth and protection during inflammatory responses in mice. EMBO J 18:5943-5952

Yan LJ, Christians ES, Liu L, Xiao X, Sohal RS, Benjamin IJ (2002) Mouse heat shock transcription factor 1 deficiency alters cardiac redox homeostasis and increases mitochondrial oxidative damage. EMBO J 21:5164-5172

Yoshida N, Liberman MC (2000) Sound conditioning reduces noiseinduced permanent threshold shift in mice. Hear Res 148:213-219

Yoshida N, Kristiansen A, Liberman MC (1999) Heat stress and protection from permanent acoustic injury in mice. J Neurosci 19:10116-10124

ZhANG YQ, SARGE KD (2007) Celastrol inhibits polyglutamine aggregation and toxicity though induction of the heat shock response. J Mol Med 85:1421-1428

Zou Y, Zhu W, Sakamoto M, Qin Y, Akazawa H, Toko H, Mizukami M, Takeda N, Minamino T, Takano H, Nagai T, Naka A, Komuro I (2003) Heat shock transcription factor 1 protects cardiomyocytes from ischemia/reperfusion injury. Circulation 108:3024-3030 